\title{
Nicotinic $\alpha 7$ Receptor Clusters on Hippocampal GABAergic Neurons: Regulation by Synaptic Activity and Neurotrophins
}

\author{
Hideki Kawai, ${ }^{*}$ Wagner Zago, ${ }^{*}$ and Darwin K. Berg \\ Neurobiology Section, Biology Division, University of California, San Diego, La Jolla, California 92093-0357
}

Nicotinic acetylcholine receptors containing the $\alpha 7$ gene product are expressed at substantial levels in the hippocampus. Because of their specific locations and their high relative calcium permeability, the receptors not only mediate cholinergic transmission in the hippocampus but also influence signaling at noncholinergic synapses. We have used fluorescently labeled $\alpha$-bungarotoxin to image $\alpha 7$-containing receptors on hippocampal neurons and to examine their regulation in culture. The highest levels of staining for such receptors were most commonly found on GABAergic interneurons identified immunohistochemically. The receptors were distributed in clusters on the soma and dendrites and were localized in part at GABAergic synapses. A 3 d blockade of electrical activity with tetrodotoxin or NMDA receptors with APV dramatically reduced the proportion of GABAergic neurons expressing high levels of receptor staining and reduced the mean number of distinguish- able receptor clusters on individual neurons. Blockade of either $\mathrm{GABA}_{A}$ receptors with bicuculline or nicotinic receptors with D-tubocurarine had no effect, although exposure to nicotine could increase the level of receptor staining. Anti-BDNF and anti-NGF antibodies produced decrements equivalent to those of tetrodotoxin and APV, whereas addition of BDNF and NGF each increased staining levels and increased the number of distinguishable receptor clusters on GABAergic neurons. The exogenous neurotrophins could not, however, overcome the effects of either tetrodotoxin or APV. The results indicate that both NMDA receptor activation and the neurotrophins BDNF and NGF are necessary to sustain the distribution patterns of $\alpha 7$-containing nicotinic receptors on GABAergic hippocampal neurons.

Key words: nicotinic; acetylcholine; receptors; hippocampal; BDNF; NGF; bungarotoxin
The hippocampus has been the subject of intense study examining mechanisms of synaptic plasticity. Central to this has been the analysis of glutamatergic transmission. Recent evidence suggests that nicotinic signaling may also contribute significantly to hippocampal function. Nicotinic acetylcholine receptors containing the $\alpha 7$ gene product ( $\alpha 7$-nAChRs) are expressed at some of their highest CNS levels in the hippocampus. Such receptors have a high relative permeability to calcium (Bertrand et al., 1993; Seguela et al., 1993) and can modulate transmitter release both from GABAergic and glutamatergic terminals in the hippocampus (Gray et al., 1996; Alkondon et al., 1997a; Radcliffe and Dani, 1998; Maggi et al., 2001). The receptors also act postsynaptically to mediate excitatory input (Alkondon et al., 1998; Frazier et al., 1998; Hefft et al., 1999; Jones et al., 1999). Depending on the neurons involved, $\alpha 7$-nAChR activation can lead to either inhibition or disinhibition of hippocampal output and can have divergent effects on synaptic plasticity as well (Fujii et al., 2000; Ji and Dani, 2000; Alkondon and Albuquerque, 2001; Buhler and Dunwiddie, 2001, 2002; Ji et al., 2001).

The consequences of $\alpha 7-\mathrm{nAChR}$ activation are likely to de-

\footnotetext{
Received May 9, 2002; revised June 27, 2002; accepted July 3, 2002.

This work was supported by National Institutes of Health Grants NS12601 and NS35469 and by Tobacco-Related Disease Research Program Grant 9RT-0221. We thank Xiao-Yun Wang for preparation of the hippocampal cultures and Lynn Ogden for performing the binding studies. H.K. is an American Heart Association Postdoctoral Fellow.

*H.K. and W.Z. contributed equally to this work.

Correspondence should be addressed to Darwin K. Berg, Neurobiology Section, Biology Division, University of California, San Diego, 9500 Gilman Drive, La Jolla, CA 92093-0357. E-mail: dberg@ucsd.edu.

H. Kawai's present address: Department of Neuroscience, Brown University, 190 Thayer Street, Providence, RI 02912.

Copyright (C) 2002 Society for Neuroscience $\quad 0270-6474 / 02 / 227903-10 \$ 15.00 / 0$
}

pend critically on receptor location and the calcium-dependent processes resident at those sites. Ultrastructural analysis suggests that $\alpha 7-n A C h R s$ are concentrated both presynaptically and postsynaptically at almost all synapses in the CA1 stratum radiatum of the hippocampus (Fabian-Fine et al.,. 2001). The anatomical distribution is consistent with reports that $\alpha 7-\mathrm{nAChR}$ activation can enhance both GABAergic and glutamatergic transmission, but further suggests that the modulation may be more complex than previously recognized. How $\alpha 7$-nAChRs become located at such sites is unknown.

Immunohistochemical staining of rat hippocampal neurons in culture reveals $\alpha 7$-nAChR clusters on neuronal somata and dendrites. The clusters often colocalize with synaptotagmin stained as a marker for presynaptic terminals (Zarei et al., 1999). Recently it has been shown that $\alpha 7$-nAChR levels on hippocampal neurons in culture can be regulated by neuregulins and that the neuregulin-induced increases in receptors also produce enhanced modulation of transmitter release (Liu et al., 2001). These results suggest that rat hippocampal cultures can be used to identify conditions that control the distribution of $\alpha 7-n A C h R s$ and influence their localization at synaptic sites.

We show here that $\alpha 7$-nAChRs can be imaged on hippocampal neurons using fluorescently labeled $\alpha$-bungarotoxin $(\alpha$-Bgt) and that the receptors are concentrated in clusters located in part at GABAergic synapses. The receptor clusters can also be found at the distal tips of filopodia-like dendritic extensions. Because synaptic activity and endogenous neurotrophins can both influence synapse formation on hippocampal neurons (McAllister et al., 1999; Schuman, 1999; Bolton et al., 2000; Schinder and Poo, 2000; Turrigiano and Nelson, 2000; Murthy et al., 2001; Tyler and Pozzo-Miller, 2001), we examined their effects on $\alpha 7$-nAChR 
clusters. We find that transmission via NMDA receptors but not via $\mathrm{GABA}_{\mathrm{A}}$ or nicotinic receptors, is required to sustain the pattern of $\alpha 7$-nAChRs. Endogenous BDNF and NGF are also required, but exogenous neurotrophins cannot compensate for NMDA receptor blockade, although they can increase cluster number when acting alone.

\section{MATERIALS AND METHODS}

Cell cultures. Hippocampal cultures were prepared from 19-d-old Sprague Dawley rat embryos as previously described for cortical cultures (Kawai and Berg, 2001). Hippocampi were removed rapidly under stereomicroscopic observation, cut into small pieces, and digested with 20 $\mathrm{U} / \mathrm{ml}$ of papain (Worthington, Lakewood, NJ) in HBSS (Invitrogen, Gaithersburg, MD) containing $0.7 \mathrm{~mm} \mathrm{CaCl}_{2}, 0.35 \mathrm{~mm}$ EDTA, 0.01 $\mathrm{mg} / \mathrm{ml}$ DNase I, $2 \mathrm{mg} / \mathrm{ml}$ L-cysteine, $10 \mathrm{~mm}$ HEPES, and $1 \mathrm{~mm}$ sodium pyruvate, at $37^{\circ} \mathrm{C}$ for $30 \mathrm{~min}$. The tissue segments were then transferred to Neurobasal medium (Invitrogen) containing $4.4 \mathrm{~mm}$ sodium bicarbonate and $21.6 \mathrm{~mm} \mathrm{NaCl}$, and triturated with a fire-polished Pasteur pipette in the presence of $0.01 \mathrm{mg} / \mathrm{ml}$ DNase I. After centrifugation for $5 \mathrm{~min}$ at $800 \times g$, the cells were resuspended in Neurobasal medium with $2 \%(\mathrm{v} / \mathrm{v})$ B-27 supplement, $0.5 \mathrm{~mm}$ L-glutamine, $50 \mathrm{U} / \mathrm{ml}$ penicillin, and $50 \mu \mathrm{g} / \mathrm{ml}$ streptomycin (Invitrogen). The cells were plated at $2 \times 10^{4}$ per $12 \mathrm{~mm}$ glass coverslip previously coated with poly-D-lysine $(>300 \mathrm{kDa}$; Sigma, St. Louis, MO). The cultures initially received the medium described above plus $10 \%$ (v/v) heat-inactivated horse serum (Gemini BioProducts, Woodland, CA). Subsequent feeding occurred twice weekly, each time replacing half the volume with medium lacking horse serum. On day 6 , the cultures received $5 \mu \mathrm{M}$ cytosine- $\beta$-D-arabinof uranoside to inhibit further proliferation of non-neuronal cells. The cultures were maintained in a humidified tissue culture incubator with $95 \%$ air and $5 \%$ $\mathrm{CO}_{2}$ until use. Where indicated, the following compounds were applied to the cells during the last $3 \mathrm{~d}$ in culture: $1 \mu \mathrm{M}$ tetrodotoxin (TTX), $50 \mu \mathrm{M}$ D-(-)-2amino-5-phosphono-valeric acid (APV), $0.5 \mu \mathrm{M}$ nicotine, $10 \mu \mathrm{M}$ D-tubocurarine (D-TC), $100 \mathrm{ng} / \mathrm{ml} \mathrm{BDNF}$ (recombinant BDNF; Chemicon, Temecula, CA), $100 \mathrm{ng} / \mathrm{ml} \mathrm{NGF}$ (2.5S; Invitrogen, Carlsbad, CA), 5 $\mathrm{ng} / \mathrm{ml}$ neuregulin (recombinant HRG1- $\beta 1$ EGF-like domain; R \& D Systems, Minneapolis, MN), $10 \mu \mathrm{g} / \mathrm{ml}$ chicken anti-BDNF functionalblocking polyclonal antibodies (Promega, Madison, WI), and $1 \mu \mathrm{g} / \mathrm{ml}$ sheep anti-NGF function-blocking polyclonal antibodies (Chemicon). Bicuculline $(20 \mu \mathrm{M})$ was applied for the last $7 \mathrm{~d}$ as was nicotine where indicated. To assess possible nonspecific effects of anti-neurotrophin antibodies, IgGs raised in sheep and chicken were incubated in the cultures and compared in the same experiments.

Labeling surface $\alpha 7-n A C h R$ s. For imaging studies, cells maintained for $19-20 \mathrm{~d}$ in culture were washed twice with Neurobasal medium plus $0.1 \%$ BSA and then incubated in the same medium containing $100 \mathrm{~nm}$ of Alexa Fluor $488 \alpha$-bungarotoxin (Alexa488- $\alpha$-Bgt; Molecular Probes, Eugene, $\mathrm{OR})$ at $37^{\circ} \mathrm{C}$ for $45 \mathrm{~min}$. Nonspecific binding was assessed by incubating the cells in either nicotine $(1 \mathrm{mM}), \alpha$-Bgt $(5 \mu \mathrm{M})$, or methyllycaconitine (MLA; $5 \mu \mathrm{M}) 10 \mathrm{~min}$ before and during the labeling with Alexa488- $\alpha$ Bgt. The cells were then washed four times in $2 \mathrm{ml}$ of Neurobasal medium and fixed for $20 \mathrm{~min}$ at room temperature in $4 \%$ paraformaldehyde in PBS. For binding studies, the cells were incubated with $5 \mathrm{nM}$ ${ }^{125} \mathrm{I}-\alpha$-Bgt $(260-390 \mathrm{cpm} / \mathrm{fmol}$; Amersham Biosciences, Buckinghamshire, UK) for $1 \mathrm{hr}$ at room temperature, rinsed, scraped in non-ionic detergent, and quantified for retained radioactivity with a gamma counter as previously described (Kawai and Berg, 2001). Nonspecific binding was determined by including $0.5 \mu \mathrm{M} \alpha$-Bgt (Molecular Probes) with the ${ }^{125} \mathrm{I}-\alpha$-Bgt; nonspecific binding did not exceed $12 \%$ of total binding and was subtracted in all cases.

Fluorescence immunocytochemistry. For immunolabeling, fixed cells were permeabilized with $0.1 \%$ Triton X-100 in PBS and then incubated with antibodies. These included a mouse anti-glutamic acid decarboxylase (GAD) monoclonal antibody (mAb; clone GAD-6 for GAD65, 1:1000; Boehringer Mannheim, Indianapolis, IN), a rabbit anti-GAD polyclonal antibody (for GAD65/67, 1:500, Chemicon), a rabbit anti$\mathrm{GABA}_{\mathrm{A}}$ receptor $\left(\mathrm{GABA}_{\mathrm{A}} \mathrm{R}\right) \alpha 1$-subunit polyclonal antibody (1:500; Upstate Biotechnology, Lake Placid, NY), a mouse anti-MAP-2 mAb (1:1000; Sigma), a goat anti- $\alpha 7-n A C h R$ polyclonal antibody (SC14447, 1:1000; Santa Cruz Biotechnology, Santa Cruz, CA), and both goat and rabbit anti-vesicular ACh transporter polyclonal antibodies $(60596 \mathrm{E}$, 1:1000; PharMingen International, San Diego, CA; Phoenix Pharmaceuticals, Belmont, CA). Nonspecific antibody binding was minimized by treatment with $5 \%$ donkey serum in PBS for $30 \mathrm{~min}$ at room temperature.
Primary antibodies were diluted in $0.1 \%$ Triton X-100 PBS and incubated with the cells for $1 \mathrm{hr}$ at $37^{\circ} \mathrm{C}$. Cells were washed three times $(10$ min intervals) in PBS and then incubated for $1 \mathrm{hr}$ at room temperature with secondary antibodies raised in goat or donkey and conjugated to Cy3 or Cy5 fluorophores (1:500 dilution in $0.1 \%$ Triton X-100 PBS; Jackson ImmunoResearch, West Grove, PA). The cells were then washed three times (10 min intervals) in PBS and mounted using anti-fade mounting solution (Vectashield; Vector Laboratories, Burlingame, CA).

Image acquisition and quantification. Digital images of fluorescently labeled cells were collected using a CCD camera mounted on a Zeiss Axiovert (63× oil-immersion objective, 1.4 numerical aperture lens) and equipped with SlideBook deconvolving software (Intelligent Imaging Innovations, Santa Monica, CA). Reconstructed images were generated from $z$-axis stacks of $100.5 \mu \mathrm{m}$ deconvolved optical sections. Controls in which one or more primary antibodies were omitted showed no significant cross-contamination among fluorescence channels. This approach allowed images to be obtained and analyzed in cases where confocal microscopy proved insufficient. Quantification of colocalized signal was performed by normalizing the intensity data among fluorescence channels (maximal intensity, 100\%), followed by subtracting the background fluorescence. Control cultures in each experiment were used to set the intensity ranges to be measured; these same ranges were then applied to all images captured in the experiment. Maximum intensities were evaluated by either of two methods with similar outcomes. One was to scan a number of the brightest spots on control cells $(\geq 10$ per neuron, $\geq 8$ neurons per experiment), recording the single highest pixel intensity within each spot, and then averaging such values to define a maximum. The alternative was to display the entire distribution of pixel intensities seen for a field of view containing a control neuron ( $\geq 8$ neuron fields analyzed) and to set the maximum to include $>99 \%$ of the pixel values. The two methods usually agreed within $10 \%$.

Measurements of cluster size, area, and number were performed using ImagePro 3.0 software (Media Cybernetics, Silver Spring, MD). Clusters were counted along dendritic segments $(\leq 45 \mu \mathrm{m}$, starting $\geq 5 \mu \mathrm{m}$ from the soma) and compared for colocalization with other markers after merging the appropriate fluorescent images. Threshold values of 0.05 $\mu \mathrm{m}^{2}$ (five contiguous pixels) and $50 \%$ of maximal intensity were chosen for defining clusters. A minimum overlap of $0.05 \mu \mathrm{m}^{2}$ (five pixels) was taken as threshold for defining colocalization of two fluorescent signals. Data were collected from two to four dendrites per neuron, and a total of five to seven randomly selected GAD-positive neurons per coverslip. Coverslips were usually analyzed in duplicate per experiment. Values were normalized to controls (percentage of controls) and are shown as mean \pm SEM of three to nine separate experiments. Statistical differences between two means were determined using the two-tailed Student's $t$ test; comparisons among more than two were determined by ANOVA. To assess the amount of codistribution that might be expected for two markers based on chance, we measured the fraction of the dendritic length (along a line segment) occupied by each and then multiplied these two values together to calculate the fraction predicted for random overlap. Nonrandom codistribution of two markers (e.g., staining for $\alpha 7$-nAChR clusters and GAD-positive terminals) was that amount of codistribution significantly greater than the amount predicted for random overlap.

In some experiments cells were divided into categories based on overall Alexa488- $\alpha$-Bgt labeling, using the following criteria. "Unlabeled" cells were those with staining intensities not significantly different from negative controls, i.e., cells co-incubated with a competing ligand. "Moderate" cells were those in which individual $\alpha 7-n A C h R$ clusters could be distinguished on the soma and dendrites as described above. The range of staining intensities varied considerably among moderate neurons but the mean pixel intensity for receptor clusters was $\sim 150$ (arbitrary units), after subtracting a nonspecific background level of 15-20. "High" cells were those in which perimeter labeling was too extensive to distinguish individual clusters. The mean pixel intensity along the perimeter of such cells was $\sim 400$, after subtracting a nonspecific background of 15-20.

Materials. Unless otherwise indicated, all drugs and compounds were purchased from Sigma.

\section{RESULTS}

\section{Imaging $\alpha 7-n A C h R s$ on hippocampal neurons}

Staining intact rat hippocampal neurons in culture with Alexa488$\alpha$-Bgt yielded specific labeling readily visualized with fluores- 

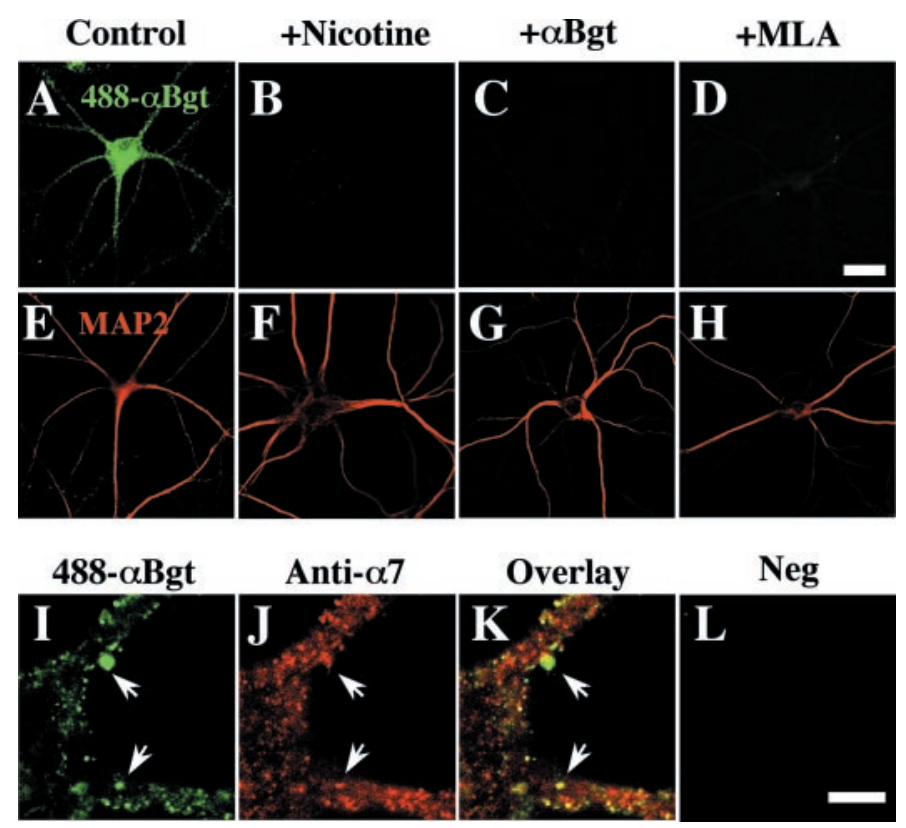

Figure 1. Specificity of Alexa488- $\alpha$-Bgt labeling of $\alpha 7$-nAChRs on hippocampal neurons in culture. Top row, Hippocampal neurons stained for $\alpha 7$-nAChRs with Alexa488- $\alpha$-Bgt (100 nM, 488- $\alpha$-Bgt, green $)$ in the absence $(A)$ or presence of nicotine $(B), \alpha$-Bgt $(C)$, or MLA $(D)$. Middle row, Same neurons as above, costained with antibodies (red) for MAP-2 $(E-H)$. The staining with Alexa488- $\alpha$-Bgt is specific for $\alpha 7$-nAChRs and reveals receptor clusters distributed over the cell body and along the proximal dendrites. Nonspecific labeling represented $<10 \%$ of average intensity along dendrites. Bottom row, Cell stained first (green) with Alexa488- $\alpha$-Bgt $(I)$, then fixed, permeabilized, and costained (red) with anti- $\alpha 7$-nAChR antibodies $(J)$, and shown in overlay $(K)$, revealing surface clusters of receptor that colabeled with both markers (arrows). Antibody staining also showed intracellular receptor protein not seen with the Alexa488- $\alpha$-Bgt staining performed on the intact cell. Substituting nonimmune $\mathrm{IgG}$ for the anti-receptor antibody produced no staining $(L)$; the cell occupied approximately the same position and area as the cell in $I-K$. Scale bars: $A-H, 20 \mu \mathrm{m} ; I-L, 5 \mu \mathrm{m}$.

cence optics and deconvolving software. The staining represented $\alpha 7$-nAChRs because it could be blocked not only by nicotine but also by either unlabeled $\alpha$-Bgt or MLA (Fig. 1, top row). The cells were identified as neurons by costaining with MAP-2 (Fig. 1, middle row). Only surface $\alpha 7$-nAChRs were labeled with the Alexa488- $\alpha$-Bgt because the toxin binding was performed on living cells before fixation and permeabilization; scanning in the $z$-axis confirmed that the staining was confined to the cell perimeter. When the labeled cells were subsequently fixed, permeabilized, and costained with a goat anti- $\alpha 7$-nAChR antibody (Paysan et al., 2000), the Alexa488- $\alpha$-Bgt staining codistributed with antibody labeling on the perimeter; additional antibody staining was found inside the cell, indicating intracellular receptor protein as well (Fig. 1, bottom row). Binding studies with ${ }^{125} \mathrm{I}-\alpha$-Bgt to quantify $\alpha 7$-nAChRs on the cells showed that the number of surface receptors increased with culture age for at least the first 3 weeks, as reported previously (Barrantes et al., 1995; Samuel et al., 1997). All subsequent experiments were performed on cells during the third week of culture.

The types of hippocampal neurons expressing detectable levels of $\alpha 7$-nAChRs were assessed by immunostaining. MAP-2 staining was used again to identify neurons in the cultures (Fig. $2 A-C$ ). Costaining for GAD revealed that $17 \pm 2 \%$ were GABAergic interneurons (mean $\pm \mathrm{SEM} ; n=14$ experiments; one or two
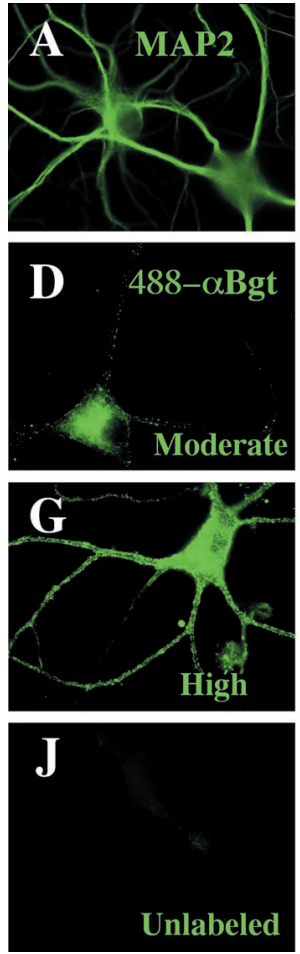
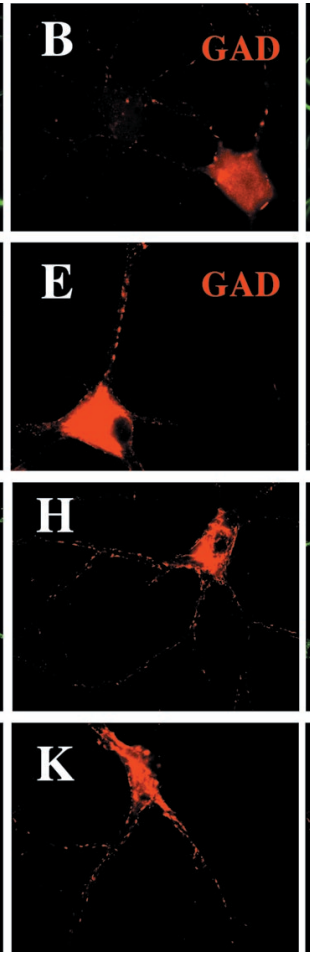

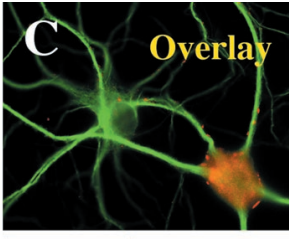

F Overlay
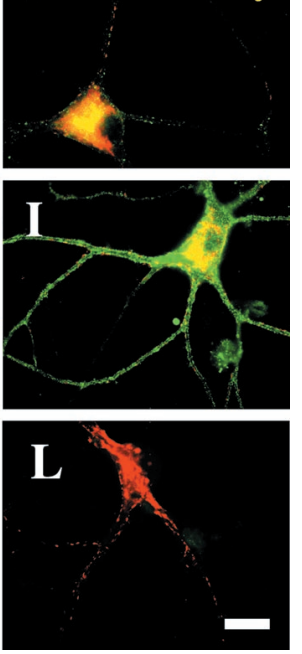

Figure 2. Cell categories for $\alpha 7$-nAChR labeling on GABAergic hippocampal neurons. Top row, Hippocampal neurons, defined by immunostaining for MAP-2 $(A)$, included examples of both GAD-positive and GAD-negative cells as putative GABAergic and glutamatergic neurons, respectively $(B)$, seen in overlay $(C)$. Second row, Example of GADpositive neuron expressing moderate levels of $\alpha 7$-nAChR labeling $(D-F)$. Third row, GAD-positive neuron expressing high level of $\alpha 7$-nAChR labeling $(G-I)$. Bottom row, Unlabeled GAD-positive neuron $(J-L)$. The relative proportions of GAD-positive cells in unlabeled, moderate, and high categories for $\alpha 7$-nAChR labeling were $32 \pm 4,53 \pm 4$, and $15 \pm 2 \%$, respectively. Values represent mean \pm SEM of 12 experiments ( 360 cells). Scale bar, $20 \mu \mathrm{m}$.

coverslips per experiment; 15 fields of view per coverslip). The remaining $83 \%$ were presumed to be glutamatergic pyramidal neurons, consistent with the composition in vivo (Olbrich and Braak, 1985; Freund and Buzsaki, 1996). Staining cultures first with Alexa488- $\alpha$-Bgt, and then rinsing, fixing, permeabilizing, and staining for GAD indicated that GABAergic interneurons were much more likely to display readily detectable levels of $\alpha 7$-nAChR labeling than were the GAD-negative neurons. This is consistent with previous findings (Liu et al., 2001). Subsequent experiments targeted the GAD-positive cells.

Examining all GABAergic neurons in the cultures indicated that $68 \pm 4 \%$ (mean $\pm \mathrm{SEM} ; n=12$ ) of them expressed levels of $\alpha 7$-nAChRs sufficient for imaging. These could be further divided into cells having moderate labeling $(53 \pm 4 \%$ of the GAD-positive neurons) and those with high labeling (15 $\pm 2 \%$ of the GAD-positive neurons). Moderate cells ranged in the level of staining intensity but shared the feature of displaying discrete receptor clusters on the soma and dendritic surfaces (Fig. 2D-F). High cells were stained more brightly, and the staining was so extensive that receptor clusters usually could not be distinguished (Fig. 2G-I). The remaining GAD-positive neurons $(32 \pm 4 \%)$ were classified as unlabeled (Fig. $2 J-L$ ) because they were equivalent to neurons in which specific binding had been blocked with a receptor antagonist. 


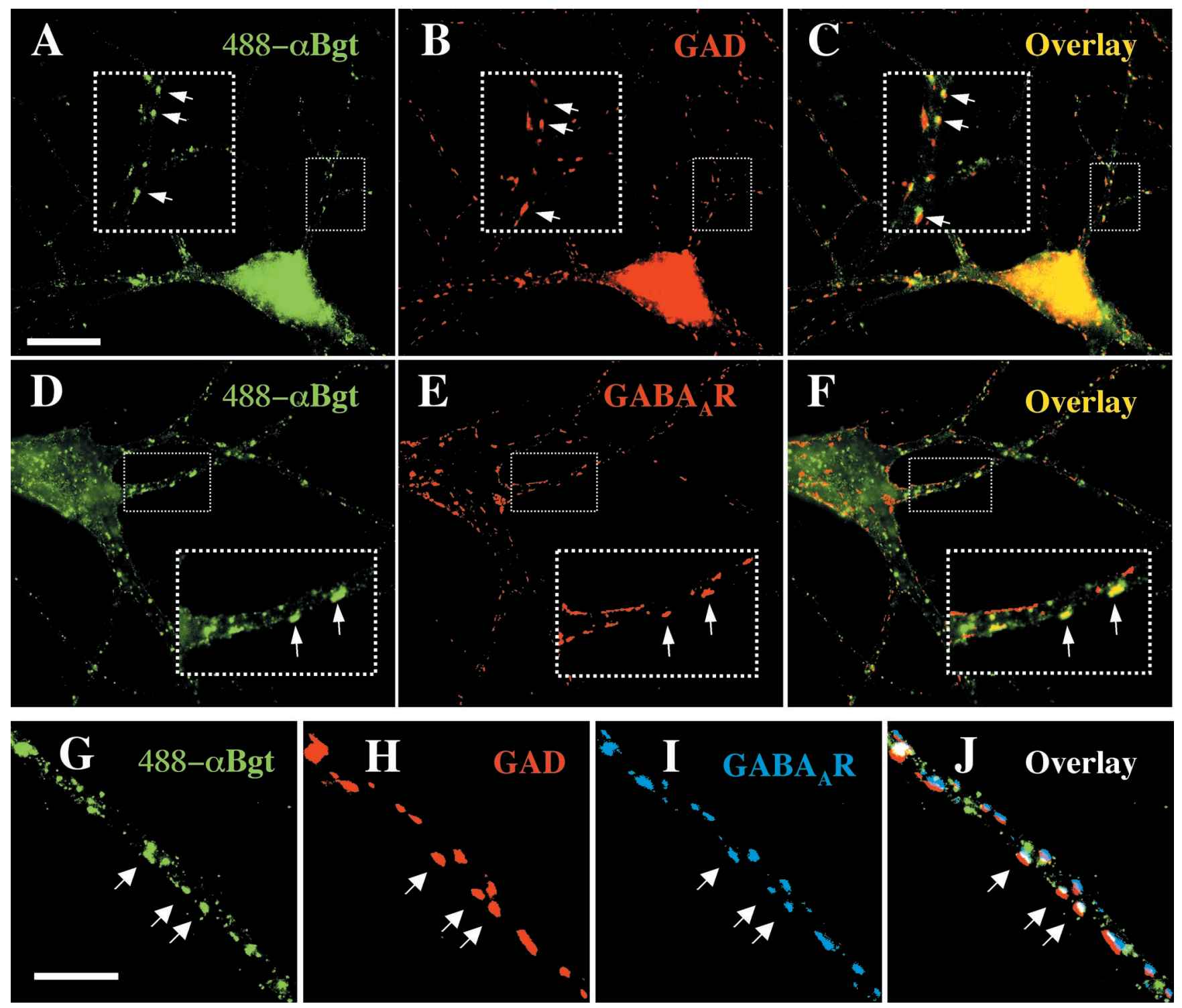

Figure 3. Clusters of $\alpha 7$-nAChRs and their location at GABAergic synapses. Cells stained with Alexa488- $\alpha$-Bgt for surface $\alpha 7$-nAChRs $(A, D$, $G)$ and costained for $\operatorname{GAD}(B, H)$ and/or $\alpha 1-\mathrm{GABA}_{\mathrm{A}} \mathrm{R}$ subunit $(E, I)$ were viewed in overlay $(C, F, J)$. Large boxes are expansions of the small boxes; arrows indicate examples of codistributed markers. A significant proportion of $\alpha 7$-nAChRs clusters on GABAergic neurons $(18 \pm 4 \%, n=11)$ are present at GABAergic synapses defined by GAD staining and colocalize with $\alpha 1-\mathrm{GABA}_{\mathrm{A}}$ Rs. Scale bars: $A-F, 20 \mu \mathrm{m} ; G-J, 10 \mu \mathrm{m}$.

\section{Clusters of $\alpha 7$-nAChRs at GABAergic synapses and on filopodia-like extensions}

Further analysis of GAD-positive neurons with moderate $\alpha 7$ $\mathrm{nAChR}$ staining demonstrated that a significant number of the $\alpha 7$-nAChR clusters were localized at GAD-positive presynaptic terminals abutting the dendrites (Fig. $3 A-C$ ). The GAD-positive terminals appeared as discrete entities and were clearly distinct from the soma staining produced by the GABAergic neuron itself. Quantitative analysis (see below) indicated the proportion of $\alpha 7$-nAChR clusters located at such terminals to be about a fifth of the total receptor clusters. This value was five times greater than the random overlap to be expected from the proportions of dendritic surface area occupied by $\alpha 7-n A C h R$ clusters on the one hand and by GAD-positive terminals on the other. No evidence for cholinergic terminals was revealed in the cultures, as detected by staining cells for the vesicular $\mathrm{ACh}$ transporter (data not shown).
In some cases the $\alpha 7-\mathrm{nAChR}$ clusters tightly overlapped with the presynaptic staining for GAD, suggesting the receptors may have been presynaptic. In other cases the $\alpha 7$-nAChR clusters were immediately adjacent to but only partially overlapping with terminal GAD staining, suggesting that the receptor clusters were mostly postsynaptic. Examining sequential optical sections in the $z$-axis supported this interpretation (data not shown). Further evidence for a postsynaptic location came from staining the cultures for $\mathrm{GABA}_{\mathrm{A}}$ receptors using antibodies specific for the $\mathrm{GABA}_{\mathrm{A}} \alpha 1$ subunit. Costaining with Alexa488- $\alpha$-Bgt for $\alpha 7$ $n A C h R s$ and with the anti- $\alpha 1$ antibody indicated numerous occasions of complete overlap (Fig. 3D-F). Triple staining for $\alpha 7$-nAChRs, $\alpha 1-$ GABA $_{\mathrm{A}} \mathrm{Rs}$, and GAD provided clear examples of complete overlap of the two receptor types juxtaposed to GAD-positive terminals (Fig. $3 G-J$ ).

Perhaps most convincing for the hypothesis that $\alpha 7-\mathrm{nAChR}$ clusters can often be postsynaptic was the following observation. 

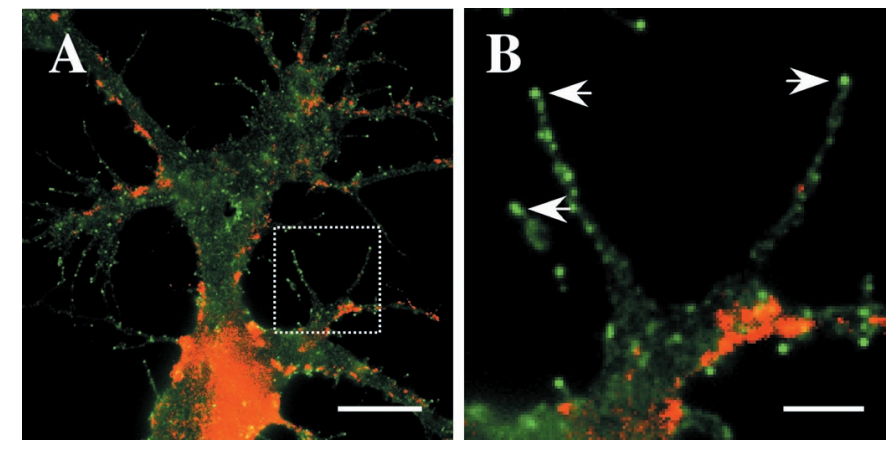

Figure 4. Clusters of $\alpha 7$-nAChRs at tips of filopodia-like structures emanating from dendrites of GABAergic interneurons. $A$, Isolated GABAergic neuron with high level of Alexa488- $\alpha$-Bgt labeling (green) costained for GAD (red) and shown in overlay. $B$, The boxed region in $A$ is shown in expansion. The $\alpha 7$-nAChR clusters present at the tips of the filopodia-like extensions (arrows) are not associated with GAD staining. Scale bars: $A, 20 \mu \mathrm{m} ; B, 5 \mu \mathrm{m}$.

GAD-positive neurons that did not themselves express $\alpha 7$ nAChRs (unlabeled category of neurons) lacked $\alpha 7-n A C h R$ clusters even at dendritic sites receiving GAD-positive terminals. Examining a total of 126 dendrites on unlabeled neurons (28 neurons, 13 experiments) yielded no detectable $\alpha 7$-nAChR clusters, although 2618 GAD-positive terminals were identified as abutting on the dendrites. In contrast, examining 108 dendrites from neurons with moderate Alexa488- $\alpha$-Bgt staining (44 neurons, 14 experiments) yielded 3691 receptor clusters, and 664 of them were associated with GAD-positive terminals which themselves numbered 1702 in all. The simplest interpretation is that most, if not all, of the $\alpha 7$-nAChR clusters detectable at GABAergic synapses on moderate neurons are provided by the postsynaptic neuron. Presynaptic $\alpha 7-n A C h R s$ are likely to be present (Alkondon et al., 1997a; Maggi et al., 2001) but may have been too sparse to score as a cluster with the current imaging criteria. A much less likely explanation for the result would be that GAD terminals cannot express presynaptic $\alpha 7$-nAChRs for some reason if the postsynaptic neuron is unable to do so. Taken together, the present results suggest a postsynaptic location for many of the $\alpha 7$-nAChR clusters observed here at GABAergic synapses, but this conclusion should be considered tentative until confirmed by ultrastructural analysis.

GAD-positive neurons with high $\alpha 7$-nAChR labeling did not permit resolution of individual receptor clusters in most cases, but examining the cells yielded an additional interesting result. In many cases, $\alpha 7$-nAChRs were found sharply concentrated at the distal tips of filopodia-like extensions emanating from the dendrites (Fig. 4). Such $\alpha 7$-nAChR clusters were not associated with $\alpha 1-\mathrm{GABA}_{\mathrm{A}}$ Rs or GAD-stained presynaptic terminals.

\section{Activity-dependent regulation of $\alpha 7-n A C h R$ levels on GABAergic neurons}

Electrical activity was necessary to sustain the $\alpha 7$-nAChR staining levels found on GABAergic hippocampal neurons. This could be seen by examining the distribution of cells among $\alpha 7-\mathrm{nAChR}$ labeling categories as described above for control neurons. Treating cultures for $3 \mathrm{~d}$ with TTX to block voltage-gated sodium channels produced a dramatic reduction in the cells with high labeling for $\alpha 7$-nAChRs and a corresponding increase in the proportion of unlabeled GAD-positive neurons (Fig. 5). Moderate cells appeared unchanged in number but did shift to lower overall levels of labeling, best revealed by quantifying the number

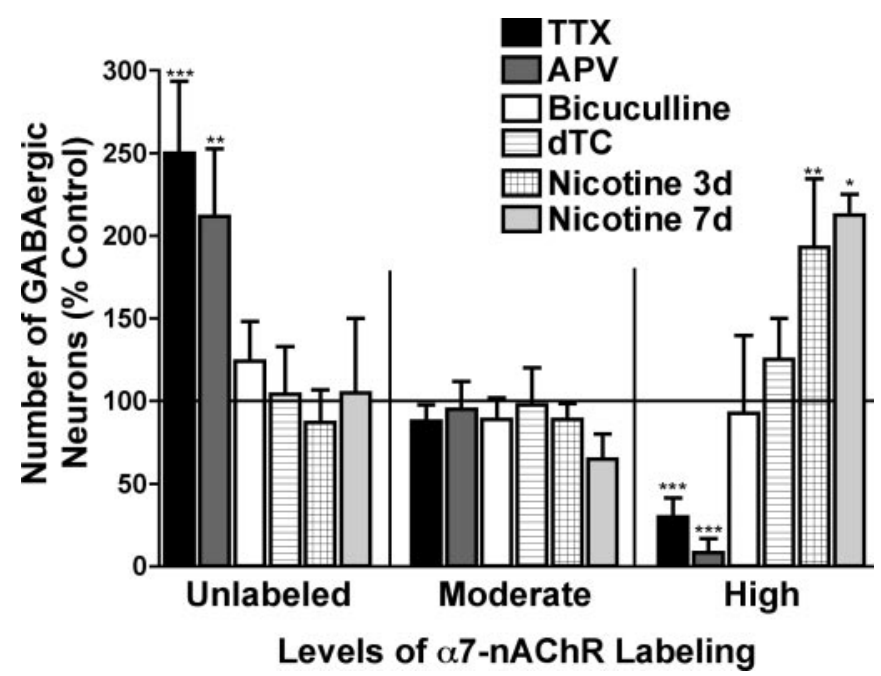

Figure 5. Activity-dependent regulation of $\alpha 7-n A C h R$ labeling. The distribution of GABAergic neurons among unlabeled, moderate, and high $\alpha 7$-nAChR labeling categories after treatment during the third week of culture with TTX $(1 \mu \mathrm{M}, 3 \mathrm{~d}), \operatorname{APV}(50 \mu \mathrm{M}, 3 \mathrm{~d})$, bicuculline $(20 \mu \mathrm{M}, 7 \mathrm{~d})$, nicotine $(0.5 \mu \mathrm{M}, 3$ and $7 \mathrm{~d})$, or D-TC $(10 \mu \mathrm{M}, 3 \mathrm{~d})$. Values are expressed as a percentage of controls from the same experiment (horizontal line) and represent the mean \pm SEM of three to nine experiments. The level of $\alpha 7-n A C h R$ labeling on GABAergic neurons depends on electrical activity and NMDA receptor activation but not on endogenous $\mathrm{GABA}_{\mathrm{A}}$ or nicotinic receptor signaling. Addition of nicotine, however, can enhance the level of labeling. Statistical differences were determined by ANOVA; ${ }^{*} p<0.05, * * p<0.01, * * * p<0.001$.

of $\alpha 7$-nAChR clusters (see below). The TTX treatment produced no decrement in the total number of neurons identified by MAP-2 staining $(99 \pm 5 \%$ of control values; mean \pm SEM, $n=5$ experiments with triplicate cultures; total of 1579 cells examined) or in the number of GABAergic neurons identified by GAD staining ( $98 \pm 4 \%$ of control values).

Blockade of NMDA receptor function produced the same effect as TTX. A 3 d exposure to APV almost completely eliminated cells from the high category; a concomitant increase occurred in unlabeled cells (Fig. 5). APV produced no change in the total number of neurons $(92 \pm 8 \%$ of control values; $n=3$ experiments) and no change in the number of GAD-positive neurons (101 $\pm 8 \%$ of control values). Blockade of GABAergic transmission with bicuculline for as long as $7 \mathrm{~d}$, on the other hand, had no effect on the proportions of GAD-positive neurons scoring either as moderate or high for $\alpha 7-n A C h R$ labeling. Blockade of nicotinic transmission with D-TC also had no effect, although low concentrations of nicotine either for a 3 or $7 \mathrm{~d}$ period increased the proportion of GAD-positive neurons with high $\alpha 7-\mathrm{nAChR}$ labeling. The results indicate that endogenous activation of NMDA receptors is essential to sustain the $\alpha 7-n A C h R$ patterns detectable here on GABAergic hippocampal neurons. Endogenous GABAergic and nicotinic signaling are much less important, although chronic nicotine exposure can increase $\alpha 7-\mathrm{nAChR}$ staining.

A different outcome was obtained in one respect when measuring the total number of $\alpha 7-n A C h R s$ on the surface of all hippocampal cells in culture. Using ${ }^{125} \mathrm{I}-\alpha$-Bgt binding to quantify $\alpha 7-n A C h R s$ on intact cells showed that the $3 \mathrm{~d}$ TTX treatment produced no change overall (99 $\pm 10 \%$ of control values; mean $\pm \mathrm{SEM} ; n=3$ experiments, three cultures per experiment). The bicuculline treatment $(7 \mathrm{~d})$ produced a small nominal in- 
crease $(131 \pm 21 \%$ of control values; $n=3)$, but the difference was not significant $(p>0.1)$. The divergence between these results with TTX and those obtained by fluorescence analysis of $\alpha 7$-nAChRs on GAD-positive neurons may have arisen from either of two sources. GAD-positive neurons are a minority of the neuronal population and may have been overshadowed by receptor changes on the population as a whole. Alternatively, the treatments may have altered the distribution of receptors, changing the proportions that were sufficiently concentrated to be detected by fluorescence imaging. In any case, the results clearly demonstrate the importance of monitoring receptor distribution on individual neurons rather than simply measuring overall levels in heterogeneous cultures.

\section{Effects of activity on $\alpha 7-n A C h R$ clusters}

To obtain a finer grain analysis of activity-dependent $\alpha 7$-nAChR regulation, we again examined $\alpha 7-\mathrm{nAChR}$ clusters on GADpositive neurons with moderate receptor labeling. Moderate cells were chosen because, as stated above, they displayed numerous clusters that could be readily resolved. GAD staining was used to distinguish GABAergic presynaptic terminals contacting the dendrites of such neurons, whereas Alexa488- $\alpha$-Bgt staining was used to visualize $\alpha 7-\mathrm{nAChR}$ clusters on the cells. Threshold values of five contiguous pixels $\left(0.05 \mu \mathrm{m}^{2}\right)$ were set both for the minimum area defining an $\alpha 7$-nAChR cluster or GAD-positive presynaptic terminal and for the minimum area defining overlap or codistribution of the two labels. Threshold values defining the minimum labeling intensity acceptable for a cluster or terminal were set at half the maximal intensities over background seen for moderate cells in control cultures in the same experiment.

By these criteria the $3 \mathrm{~d}$ treatment with either TTX or APV produced no change in the mean size either of GAD-positive terminals abutting the neurons or of $\alpha 7$-nAChR clusters themselves (Fig. 6). Both treatments did, however, produce large decreases in the number of $\alpha 7$-nAChR clusters (Fig. 6) without changing the number of GAD-positive terminals (data not shown). Bicuculline treatment ( $7 \mathrm{~d}$ ) increased the mean size of GAD-positive terminals but had no effect on the size or number of $\alpha 7$-nAChR clusters. Nicotine treatment for $3 \mathrm{~d}$ had no effect on GAD-positive terminals but increased both the mean size and number of $\alpha 7$-AChR clusters (Fig. 6). Neither bicuculline nor nicotine significantly altered the proportion of $\alpha 7-\mathrm{nAChR}$ clusters found at GABAergic synapses. Thus, $25 \pm 4$ and $22 \pm 8 \%$ ( $n=4$ experiments) of the $\alpha 7$-nAChR clusters on GABAergic neurons from bicuculline- and nicotine-treated cultures, respectively, were located at GAD-positive terminals, whereas $18 \pm 4 \%$ ( $n=11$ experiments) were so in control cultures. It was not possible to determine whether TTX or APV preferentially affected $\alpha 7$-nAChR clusters at GABAergic synapses because of the small residual numbers of clusters in these cases. When sufficient clusters were present for analysis (e.g., controls and cells treated with bicuculline, D-TC, or nicotine), the incidence of colocalization for $\alpha 7$-nAChR clusters and GAD-positive terminals was at least five times that expected from random occurrence based on the proportion of dendritic surface occupied by each population.

The results indicate that elimination of action potentials or blockade of NMDA receptors shifts cells to lower categories of labeling and reduces the number of detectable $\alpha 7-\mathrm{nAChR}$ clusters. Analyzing the distribution of clusters after triply staining for $\alpha 7$-nAChRs, GAD, and $\alpha 1-\mathrm{GABA}_{\mathrm{A}}$ Rs yielded an additional conclusion. On neurons that expressed both classes of receptors, $\alpha 1-\mathrm{GABA}_{\mathrm{A}} \mathrm{R}$ clusters were found associated with $58 \pm 12 \%$ of

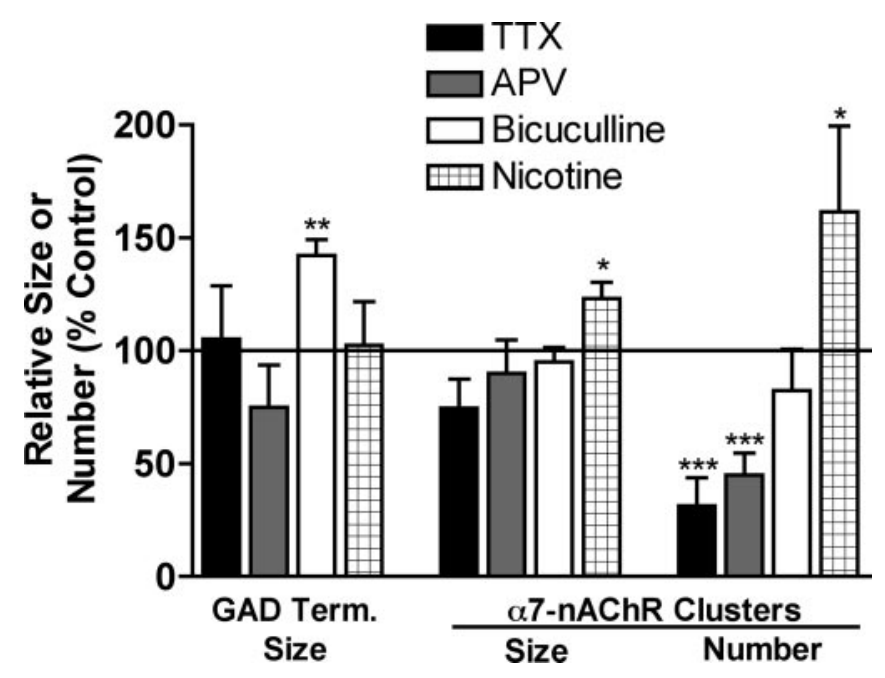

Figure 6. Activity-dependent regulation of $\alpha 7-\mathrm{nAChR}$ clusters. Shown are the normalized values for the mean size of either GAD-positive terminals or $\alpha 7-\mathrm{nAChR}$ clusters or the mean number of $\alpha 7-\mathrm{nAChR}$ clusters distributed along the dendrites of GABAergic neurons having moderate levels of $\alpha 7-\mathrm{nAChR}$ labeling. Cultures were treated for $3 \mathrm{~d}$ with TTX $(1 \mu \mathrm{M})$, APV $(50 \mu \mathrm{M})$, bicuculline $(20 \mu \mathrm{M})$, or nicotine $(0.5 \mu \mathrm{M})$. Both TTX and APV decrease while nicotine increases the number of $\alpha 7$-nAChR clusters; only nicotine increases mean cluster size. Only bicuculline increases mean GAD terminal size, but it has no effect on the mean size or number of $\alpha 7-\mathrm{nAChR}$ clusters. Values are expressed as a percentage of controls from the same experiment (horizontal line) and represent the mean \pm SEM of four to nine experiments. Controls had $45 \pm 5 \alpha 7$-nAChR clusters per $100 \mu \mathrm{m}$ dendritic length and mean sizes of $0.18 \pm 0.02$ and $0.34 \pm 0.02 \mu \mathrm{m}^{2}$ for the $\alpha 7-\mathrm{nAChR}$ clusters and GADpositive terminals, respectively ( $n=7$ experiments). Statistical differences were determined by ANOVA; ${ }^{*} p<0.05$, ** $p<0.01$, *** $p<0.001$.

the GAD-positive terminals abutting the dendrites (eight cells, four experiments). On the same neurons, $\alpha 7-\mathrm{nAChR}$ clusters were associated with $38 \pm 18 \%$ of the GAD-positive terminals. Both kinds of receptor clusters co-localized at $29 \pm 18 \%$ of the GAD-positive terminals. This value is consistent with the two classes of receptors distributing independently at the synapses and indicates that their presence is not mutually exclusive.

\section{Neurotrophin-dependent regulation of $\alpha 7-n A C h R s$}

The neurotrophins BDNF and NGF are both produced by hippocampal neurons and play important roles in synaptic development and plasticity in the hippocampus (McAllister et al., 1999; Schuman, 1999; Schinder and Poo, 2000). Both can enhance overall excitation in the cultures (Bolton et al., 2000; Tyler and Pozzo-Miller, 2001; Kovalchuk et al., 2001) and are regulated in turn by synaptic activity (Zafra et al., 1991; Lauterborn et al., 2000; Hartmann et al., 2001). Neuregulin upregulates functional $\alpha 7$-nAChRs on hippocampal neurons in culture (Liu et al., 2001), and BDNF can induce neuregulin release in other systems (Loeb and Fischbach, 1997; Loeb et al., 2002). These observations motivated us to test the effects of neuregulin in the imaging assays used here and to examine the roles of BDNF and NGF in $\alpha 7$-nAChR regulation. Exposing hippocampal neurons to neuregulin (1- $\beta 1$ isoform) for $3 \mathrm{~d}$ produced significant increases in the proportion of GAD-positive neurons expressing high $\alpha 7$ nAChR labeling (Fig. 7). This mirrored the neuregulin effects

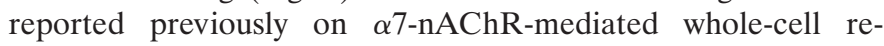
sponses (Liu et al., 2001). Compensatory decreases were seen in the unlabeled and moderate categories of GAD-positive neurons (data not shown). Treatment with either BDNF or NGF pro- 


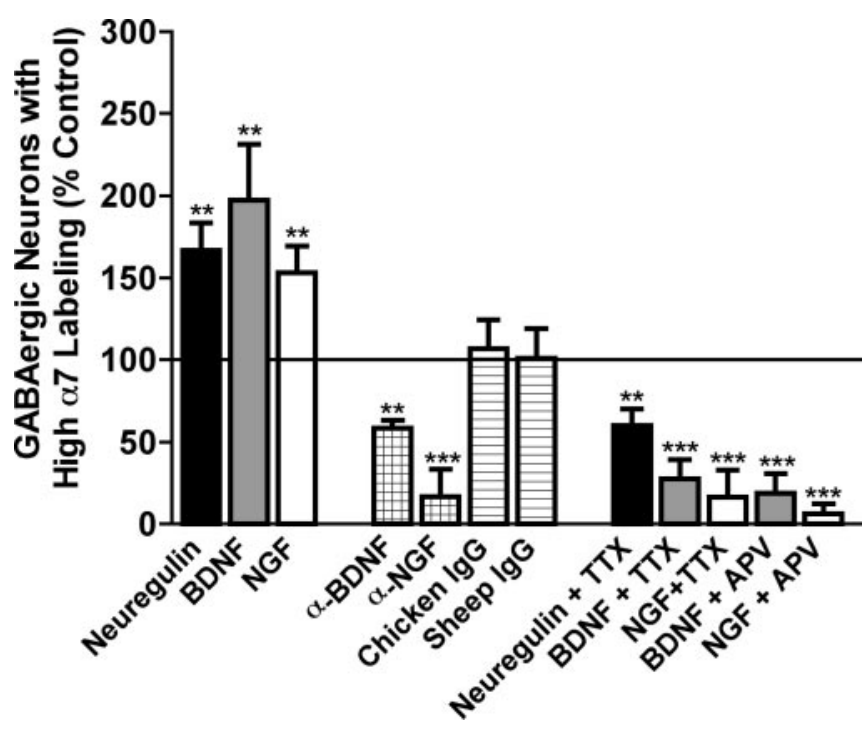

Figure 7. Neurotrophin regulation of $\alpha 7-\mathrm{nAChR}$ labeling. The distribution of GABAergic neurons among $\alpha 7$-nAChR labeling categories was analyzed as in Figure 5 after treating cells for $3 \mathrm{~d}$ with neuregulin $(5 \mathrm{nM})$, BDNF $(100 \mathrm{ng} / \mathrm{ml})$, NGF $(100 \mathrm{ng} / \mathrm{ml})$, chicken anti-BDNF antibodies, sheep anti-NGF antibodies, both chicken and sheep nonimmune $\operatorname{IgG}$ (negative controls), and where indicated, either TTX (1 $\mu \mathrm{M})$ or APV (50 $\mu \mathrm{M})$ as well. Shown here are the results obtained for cells in the high labeling category. Values are expressed as a percentage of controls from the same experiment (horizontal line) and represent the mean \pm SEM of four to nine experiments. Neuregulin, BDNF, and NGF each elevate the level of $\alpha 7$-nAChR labeling while anti-BDNF, and anti-NGF decrease it. The neurotrophins are unable to overcome the negative effects of either TTX or APV. Neuregulin was unable to overcome TTX (not significantly different from TTX alone; TTX data from Fig. 5). Statistical differences were determined by ANOVA; ${ }^{* *} p<0.01$, ${ }^{* * *} p<0.001$.

duced the same increases as neuregulin (Fig. 7). No further increase was seen when BDNF and neuregulin were combined $(192 \pm 22,175 \pm 25$, and $163 \pm 13 \%$ for BDNF, neuregulin, and $\mathrm{BDNF}+$ neuregulin treatments, respectively, normalizing the data for control values; mean \pm SEM with $n=4$ cultures, 80 cells). Anti-BDNF and anti-NGF antibodies each significantly decreased the proportion of highly labeled GAD-positive neurons (Fig. 7). The results suggest that endogenous BDNF and NGF contribute to $\alpha 7$-nAChR levels on GABAergic neurons. Neither BDNF nor NGF, when added to the cultures however, could overcome the effects of either TTX or APV (Fig. 7). Increasing the concentration of BDNF 10-fold did not alter the outcome (data not shown). Neuregulin was also ineffective against TTX.

Neurotrophin effects were further evaluated by examining the number and location of $\alpha 7$-nAChR clusters. GABAergic neurons with moderate $\alpha 7$-nAChR labeling were again chosen because individual receptor clusters could be readily quantified. BDNF, NGF, and neuregulin each had little effect on the size or number of GAD-positive terminals (data not shown), but each increased the number of $\alpha 7$-nAChR clusters (Fig. 8). BDNF also caused a small increase in the mean size of $\alpha 7$-nAChR clusters (data not shown). Treating the neurons with either anti-BDNF or antiNGF antiserum had the opposite effect, reducing the numbers of $\alpha 7$-nAChR clusters (Fig. 8). Nonimmune IgG used as negative controls had no effect. Importantly, neither BDNF nor NGF were able to overcome the effects of either TTX or APV on the number of $\alpha 7$-nAChR clusters (Fig. 8).

A qualitatively similar pattern was seen when counting only $\alpha 7$-nAChR clusters localized at GAD-positive terminals. Whereas

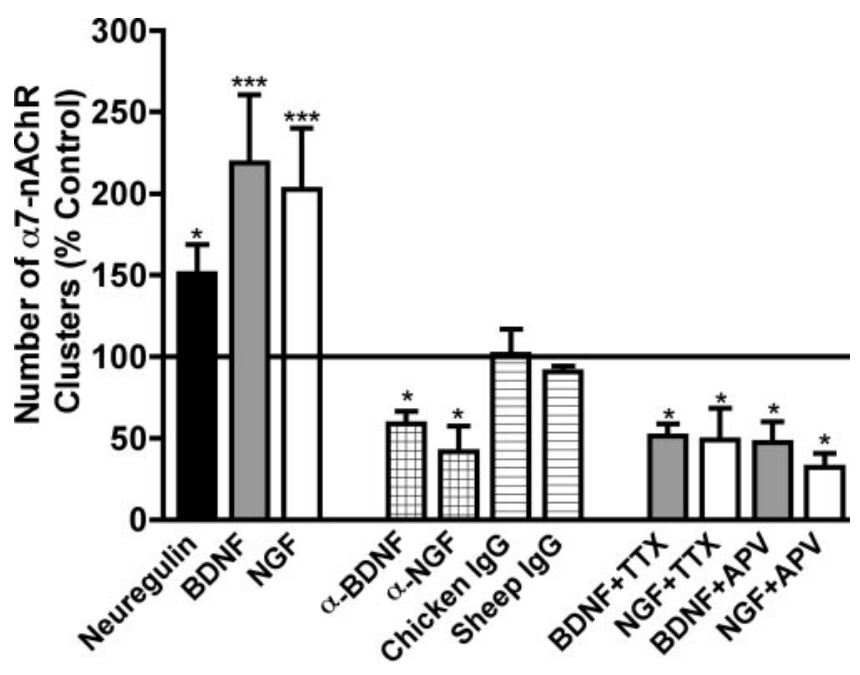

Figure 8. Neurotrophin regulation of $\alpha 7-\mathrm{nAChR}$ clusters. The numbers of $\alpha 7$-nAChR clusters per $100 \mu \mathrm{m}$ dendritic length on GABAergic neurons are expressed as a percentage of controls from the same experiment. Values represent the mean \pm SEM of four to nine experiments. Conditions and agents are the same as in Figure 7. Neuregulin, BDNF, and NGF each increase the total number of $\alpha 7$-nAChR clusters, whereas anti-BDNF and anti-NGF decrease them. The neurotrophins are unable to overcome the negative effects of either TTX or APV. Statistical differences were determined by ANOVA; ${ }^{*} p<0.05,{ }^{* * *} p<0.001$.

control cells had $8.0 \pm 1.0$ such "co-clusters" per $100 \mu \mathrm{m}$ dendritic length (32 neurons, 10 experiments), cells treated with TTX, APV, anti-BDNF, or anti-NGF each had much reduced numbers $(2.7 \pm$ $1.0,0.5 \pm 0.3,2.8 \pm 0.3$, and $1.0 \pm 0.4$, respectively). In fact for several of the treatments, the number of $\alpha 7-\mathrm{nAChR}$ clusters at GAD-positive terminals was not significantly different from that predicted for random occurrence based on the total number of clusters and GAD-positive terminals along the dendrite. Both $\mathrm{BDNF}$ and NGF increased the number of clusters at GAD-positive terminals ( $16 \pm 3$ and $12 \pm 2 / 100 \mu \mathrm{m}$, respectively) but neither could overcome the effects of APV $(1.2 \pm 0.2$ and $0.6 \pm 0.3$, respectively). The overall results, both from cluster analysis on moderate cells and from distribution analysis of cells among labeling categories, are in agreement. Neurotrophins are necessary, but not sufficient in the absence of either electrical activity in general or NMDA receptor activation in particular, to sustain $\alpha 7-\mathrm{nAChR}$ distribution patterns on the neurons.

\section{DISCUSSION}

The principal findings reported here are first that fluorescentlylabeled $\alpha$-Bgt can be used to visualize $\alpha 7$-nAChRs on the surface of hippocampal neurons in culture and that the receptors are arranged in clusters localized in part at GABAergic synapses. Second, spontaneous electrical activity and NMDA receptor activation are essential for sustaining the receptor clusters, including those at GABAergic synapses. Third, endogenous BDNF and NGF also are required, but exogenous BDNF or NGF cannot overcome the downregulation caused by blockade of NMDA receptors. Several models can account for the results including the possibilities that BDNF and NGF act upstream of NMDA receptors, perhaps increasing excitation in the cultures as suggested in other situations (Bolton et al., 2000; Tyler and PozzoMiller, 2001; Kovalchuk et al., 2001) or that they are required in parallel with activity. GABAergic neurons have been widely recognized as targets of $\alpha 7-\mathrm{nAChR}$ signaling. Presynaptic $\alpha 7$ - 
nAChRs on the neurons modulate GABA release while somatodendritic $\alpha 7$-nAChRs mediate synaptic input to the neurons and influence their participation in hippocampal circuits (Alkondon et al., 1997a, 1998; Frazier et al., 1998; Hefft et al., 1999; Jones et al., 1999; Ji and Dani, 2000; Alkondon and Albuquerque, 2001; Buhler and Dunwiddie, 2001, 2002; Ji et al., 2001; Maggi et al., 2001). Patch-clamp recording suggests that GABAergic interneurons have the highest whole-cell $\alpha 7$-nAChR responses in hippocampal cultures (Liu et al., 2001). The present studies show that GABAergic neurons express the highest incidence of surface $\alpha 7$-nAChRs detectable by fluorescence imaging, a feature that facilitated the analysis of receptor distribution on the cells. The receptors can also be found on glutamatergic neurons, however, and recent ultrastructural studies in situ show them to be localized at glutamatergic synapses as well (Fabian-Fine et al., 2001; Levy and Aoki, 2002).

Costaining for GAD and $\alpha 7$-nAChRs made clear the nonrandom distribution of $\alpha 7$-nAChRs clusters at presumed GABAergic synapses defined by GAD-positive terminals abutting the dendrites. Triply staining for GAD, $\alpha 7-n A C h R s$, and $\alpha 1-\mathrm{GABA}_{\mathrm{A}} \mathrm{Rs}$ indicated that the two types of receptors were not mutually exclusive in their clustering at individual GABAergic synapses. This is quite different from the pattern reported for misdirected receptors on isolated neurons that are constrained to receive autapses as their only innervation (Rao et al., 2000). In that case inappropriate receptors could be found at some synapses (e.g., GABA receptors opposite glutamatergic terminals) but not colocalized with correct receptors (i.e., glutamate receptors) at the same synapses. In the present studies the cultures were heterogeneous, the neurons were multiply innervated, and the $\alpha 7$ nAChR clusters did not exclude the expected transmitter receptor.

Certainly presynaptic $\alpha 7$-nAChRs would be expected at hippocampal GABAergic synapses, judging from electrophysiological studies. The $\alpha 7-n A C h R$ clusters imaged here, however, seemed more likely to be postsynaptic for the most part. This was suggested by the distribution of receptors in three-dimensional space, as seen in stacks of optical sections and by the comparative distributions of $\alpha 7-n A C h R s, \mathrm{GABA}_{\mathrm{A}}-\alpha 1$ receptors, and presynaptic GAD staining in triple-stain experiments. It was also strongly suggested by the finding that detectable $\alpha 7-n A C h R$ clusters were not associated with GAD-positive terminals if the terminals contacted dendrites from neurons not expressing detectable $\alpha 7$-nAChRs themselves. Alternative explanations for this latter finding exist but are less plausible. The imaging studies do not, of course, exclude the presence of presynaptic $\alpha 7$-nAChRs but do suggest that the staining intensity associated with them is usually less than the threshold set here for defining fluorescently labeled $\alpha 7$-nAChR clusters. Indeed, the ultrastructural studies cited above indicate the presence of both presynaptic and postsynaptic $\alpha 7$-nAChR clusters in the adult hippocampus. Ultrastructural analysis will probably also be required here to distinguish unambiguously between presynaptic and postsynaptic $\alpha 7$-nAChRs in culture.

Neuronal activity had pronounced effects on the pattern of $\alpha 7$-nAChRs. A $3 \mathrm{~d}$ exposure to TTX did not alter the total number of surface $\alpha 7$-nAChRs in culture as measured by ${ }^{125} \mathrm{I}-\alpha$ Bgt binding, but did markedly reduce $\alpha 7$-nAChR staining levels and cluster abundance on GABAergic neurons. The treatment may have dispersed $\alpha 7-\mathrm{nAChR}$ clusters, causing receptor density to be subthreshold for detection by fluorescence. Alternatively, reductions in the number of $\alpha 7$-nAChRs on GABAergic neurons may have been overshadowed by increases in receptors on other cell populations in the cultures. Blockade of NMDA receptors with APV produced reductions at least as severe as did TTX, but it would be premature to conclude that all of the regulatory effects of neuronal activity were mediated through NMDA receptors.

Surprisingly, blockade of $\mathrm{GABA}_{\mathrm{A}}$ receptors with bicuculline had no effect on $\alpha 7$-nAChR staining patterns even though a significant fraction of the $\alpha 7-\mathrm{nAChR}$ clusters were located at GABAergic synapses. The normal GABA-mediated maturation of the chloride gradient should already have occurred before the bicuculline treatment (Ganguly et al., 2001). Blockade of nicotinic receptors with D-TC also had no obvious effect, although the culture medium contained sufficient choline to partially desensitize the receptors (Alkondon et al., 1997b). Absent from the cultures was the septal input which provides the major cholinergic innervation of the hippocampus in vivo, and staining for vesicular ACh transporter failed to detect cholinergic terminals in the cultures. Chronic nicotine exposure, however, did upregulate the level of staining, consistent with other studies on CNS $\alpha 7$ nAChRs (Barrantes et al., 1995; Peng et al., 1997; Kawai and Berg, 2001), and suggests that cholinergic input could play a role in vivo.

Perhaps most interesting are the effects of BDNF and NGF. Both were attractive candidates for mediating activity-dependent regulation of $\alpha 7-\mathrm{nAChR}$ clusters. BDNF and NGF are expressed in the hippocampus and both can influence synapse formation (McAllister et al., 1999; Schuman, 1999; Schinder and Poo, 2000). BDNF can enhance neuregulin release at the neuromuscular junction, and neuregulin upregulates functional $\alpha 7-n A C h R s$ on hippocampal neurons (Loeb and Fischbach, 1997; Liu et al., 2001; Loeb et al., 2002). Moreover, chronic excitation increases the expression of BDNF and NGF by hippocampal cells. The present studies show that BDNF and NGF can each increase the number of $\alpha 7$-nAChR clusters on GABAergic hippocampal neurons and that anti-BDNF and anti-NGF antisera each reduce the number. The latter results argue strongly for a neurotrophin role in regulating $\alpha 7$-nAChRs.

Neither BDNF nor NGF, when supplied exogenously, could overcome the effects of either TTX or APV. One possibility, as cited above, is that the neurotrophins act upstream of NMDA receptors. But neurotrophins are known to have multiple effects and sites of action in the hippocampus (McAllister et al., 1999; Schuman, 1999; Schinder and Poo, 2000). Accordingly, other possibilities that must be considered are that the neurotrophins are necessary but not sufficient or that they must act locally or that their signaling is compromised somehow by NMDA receptor blockade (e.g., trk receptor downregulation). Still it is attractive to consider that a neurotrophin-mediated enhancement of activity might drive neuregulin release which, in turn, regulates $\alpha 7$ nAChRs. BDNF and neuregulin are not additive in their effects, and preliminary results suggest that exogenous neuregulin can overcome the effects of anti-BDNF antiserum on $\alpha 7-\mathrm{nAChR}$ cluster abundance (W. M. Zago and D. K. Berg, unpublished results). These observations support a downstream site of action for neuregulin. Where NMDA receptors participate in the pathway and exactly how the neurotrophins and neuregulin exert their effects have yet to be determined.

Chronic blockade of excitatory activity in hippocampal cultures increases the capacity for excitation by altering both presynaptic and postsynaptic elements at glutamatergic synapses (Schinder and Poo, 2000; Turrigiano and Nelson, 2000; Murthy et al., 2001). This homeostatic adaptation depends on AMPA receptor signaling 
rather than on NMDA receptors. NMDA receptors commonly mediate other types of activity-dependent synaptic plasticity in the hippocampus. Nonetheless, the TTX- and APV-mediated reductions seen here in $\alpha 7$-nAChR clusters on GABAergic neurons could be viewed as homeostatic compensation if the receptor clusters normally enhance GABAergic inhibitory signaling. Although this is certainly true for presynaptic $\alpha 7$-nAChRs (Alkondon et al., 1997a; Maggi et al., 2001), it is less clear for postsynaptic $\alpha 7$-nAChRs at GABAergic synapses. Because GABAergic neurons, however, were the focus of the present study, it might be argued that any reduction in excitatory input to the cells, including that via $\alpha 7$-nAChRs, could represent a compensatory mechanism because it would ultimately reduce output from these inhibitory neurons.

Key questions remain about the physiological roles of $\alpha 7$ nAChR clusters at noncholinergic synapses. The fact that such clusters persist in the adult suggests they provide a continuing function. Particularly interesting are postsynaptic $\alpha 7-\mathrm{nAChR}$ clusters at GABAergic synapses because the postsynaptic clusters should oppose the effect of presynaptic $\alpha 7$-nAChRs on inhibitory signaling. This opposition would be acute if both classes of receptors are activated in the same time frame, as should occur if ACh participates in volume transmission made possible by the diffuse cholinergic projection of the medial septum to the hippocampus (McKinney et al., 1983; Frotscher and Leranth, 1985; Descarries et al., 1997; Descarries, 1998; Zoli et al., 1999) (but see Turrini et al., 2001). Equally intriguing are the $\alpha 7$-nAChR clusters found at the tips of filopodia-like extensions emanating from GABAergic neuron dendrites. Dendritic filopodia are candidates for synaptic precursor structures (Fiala et al., 1998; Jontes and Smith, 2000; Cline, 2001). What $\alpha 7$-nAChRs do for such structures will be interesting to determine.

\section{REFERENCES}

Alkondon M, Albuquerque EX (2001) Nicotinic acetylcholine receptors $\alpha 7$ and $\alpha 4 \beta 2$ subtypes differentially control GABAergic input to CA1 neurons in rat hippocampus. J Neurophysiol 86:3043-3055.

Alkondon M, Pereira EFR, Barbosa CTF, Albuquerque EX (1997a) Neuronal nicotinic acetylcholine receptor activation modulates $\gamma$-aminobutyric acid release from CA1 neurons of rat hippocampal slices. J Pharmacol Exp Ther 283:1396-1411.

Alkondon M, Pereira EFR, Cortes WS, Maelicke A, Albuquerque EX (1997b) Choline is a selective agonist of $\alpha 7$ nicotinic acetylcholine receptors in the rat brain neurons. Eur J Neurosci 9:2734-2742.

Alkondon M, Pereira EFR, Albuquerque EX (1998) $\alpha$-Bungarotoxinand methyllycaconitine-sensitive nicotinic receptors mediate fast synaptic transmission in interneurons of rat hippocampal slices. Brain Res 810:257-263.

Barrantes GE, Roger AT, Lindstrom J, Wonnacott S (1995) $\alpha$-Bungarotoxin binding sites in rat hippocampal and cortical cultures: initial characterization, colocalization with $\alpha 7$ subunits and upregulation by chronic nicotine treatment. Brain Res 672:228-236.

Bertrand D, Galzi JL, Devillers-Thiéry A, Bertrand S, Changeux JP (1993) Mutations at two distinct sites within the channel domain M2 alter calcium permeability of neuronal $\alpha 7$ nicotinic receptor. Proc Natl Acad Sci USA 90:6971-6975.

Bolton MM, Pittman AJ, Lo DC (2000) Brain-derived neurotrophic factor differentially regulates excitatory and inhibitory synaptic transmission in hippocampal cultures. J Neurosci 20:3221-3232.

Buhler AV, Dunwiddie TV (2001) Regulation of the activity of hippocampal stratum oriens interneurons by $\alpha 7$ nicotinic acetylcholine receptors. Neuroscience 106:55-67.

Buhler AV, Dunwiddie TV (2002) $\alpha 7$ Nicotinic acetylcholine receptors on GABAergic interneurons evoke dendritic and somatic inhibition of hippocampal neurons. J Neurophysiol 87:548-557.

Cline HT (2001) Dendritic arbor development and synaptogenesis. Curr Opin Neurobiol 11:118-126.

Descarries L (1998) The hypothesis of an ambient level of acetylcholine in the central nervous system. J Physiol (Paris) 92:215-220.

Descarries L, Gisiger V, Steriade M (1997) Diff use transmission by acetylcholine in the CNS. Prog Neurobiol 53:603-625.

Fabian-Fine R, Skehel P, Errington ML, Davies HA, Sher E, Stewart
MG, Fine A (2001) Ultrastructural distribution of the $\alpha 7$ nicotinic acetylcholine receptor subunit in rat hippocampus. J Neurosci 21:7993-8003.

Fiala JC, Feinberg M, Popov V, Harris KM (1998) Synaptogenesis via dendritic filopodia in developing hippocampal area CA1. J Neurosci 18:8900-8911.

Frazier CJ, Buhler AV, Weiner JL, Dunwiddie TV (1998) Synaptic potentials mediated via $\alpha$-bungarotoxin-sensitive nicotinic acetylcholine receptors in rat hippocampal interneurons. $J$ Neurosci 18:8228-8235.

Freund TF, Buzsaki G (1996) Interneurons of the hippocampus. Hippocampus 6:347-470.

Frotscher M, Leranth C (1985) Cholinergic innervation of the rat hippocampus as revealed by choline acetyltransferase immunocytochemistry: a combined light and electron microscopic study. J Comp Neurol 239:237-246.

Fujii S, Ji Z, Sumikawa K (2000) Inactivation of $\alpha 7 \mathrm{ACh}$ receptors and activation of non- $\alpha 7 \mathrm{ACh}$ receptors both contribute to long term potentiation induction in the hippocampal CA1 region. Neurosci Lett 286:134-138.

Ganguly K, Schinder AF, Wong ST, Poo Mm (2001) GABA itself promotes the developmental switch of neuronal GABAergic responses from excitation to inhibition. Cell 105:521-532.

Gray R, Rajan AS, Radcliffe KA, Yakehiro M, Dani JA (1996) Hippocampal synaptic transmission enhanced by low concentrations of nicotine. Nature 383:713-716.

Hartmann M, Heumann R, Lessmann V (2001) Synaptic secretion of BDNF after high-frequency stimulation of glutamatergic synapses. EMBO J 20:5887-5897.

Hefft S, Hulo S, Bertrand D, Muller D (1999) Synaptic transmission at nicotinic acetylcholine receptors in rat hippocampal organotypic cultures and slices. J Physiol (Lond) 515:769-776.

Ji D, Dani JA (2000) Inhibition and disinhibition of pyramidal neurons by activation of nicotinic receptors on hippocampal interneurons. J Neurophysiol 83:2682-2690.

Ji D, Lape R, Dani JA (2001) Timing and location of nicotinic activity enhances or depresses hippocampal synaptic plasticity. Neuron 31:131-141.

Jones S, Sudweeks S, Yakel JL (1999) Nicotinic receptors in the brain: correlating physiology with function. Trends Neurosci 22:555-561.

Jontes JD, Smith SJ (2000) Filopodia, spines, and the generation of synaptic diversity. Neuron 27:11-14.

Kawai H, Berg DK (2001) Nicotinic acetylcholine receptors containing $\alpha 7$ subunits on rat cortical neurons do not undergo long-lasting inactivation even when up-regulated by chronic nicotine exposure. J Neurochem 78:1367-1378.

Kovalchuk Y, Hanse E, Kafitz KW, Konnerth A (2001) Postsynaptic induction of BDNF-mediated long-term potentiation. Science 295:1729-1734.

Lauterborn JC, Lynch G, Vanderklish P, Arai A, Gall CM (2000) Positive modulation of AMPA receptors increases neurotrophin expression by hippocampal and cortical neurons. J Neurosci 20:8-21.

Levy RB, Aoki C (2002) $\alpha 7$ Nicotinic acetylcholine receptors occur at postsynaptic densities of AMPA receptor-positive and -negative excitatory synapses in rat sensory cortex. J Neurosci 22:5001-5015.

Liu Y, Ford B, Mann MA, Fischbach GD (2001) Neuregulins increase $\alpha 7$ nicotinic acetylcholine receptors and enhance excitatory synaptic transmission in GABAergic interneurons of the hippocampus. J Neurosci 21:5660-5669.

Loeb JA, Fischbach GD (1997) Neurotrophic factors increase neuregulin expression in embryonic ventral spinal cord neurons. J Neurosci 17:1416-1424.

Loeb JA, Hmadcha A, Fischbach GD, Land SJ, Zakarian VL (2002) Neuregulin expression at neuromuscular synapses is modulated by synaptic activity and neurotrophic factors. J Neurosci 22:2206-2214.

Maggi L, Sher E, Cherubini E (2001) Regulation of GABA release by nicotinic acetylcholine receptors in the neonatal rat hippocampus. J Physiol (Lond) 536:89-100.

McAllister AK, Katz LC, Lo DC (1999) Neurotrophins and synaptic plasticity. Annu Rev Neurosci 22:295-318.

McKinney M, Coyle JT, Hedreen JC (1983) Topographic analysis of the innervation of the rat neocortex and hippocampus by the basal forebrain cholinergic system. J Comp Neurol 217:103-121.

Murthy VN, Schikorski T, Stevens CF, Z hu Y (2001) Inactivity produces increases in neurotransmitter release and synapse size. Neuron 32:673-682.

Olbrich HG, Braak H (1985) Ratio of pyramidal cells versus nonpyramidal cells in sector CA1 of the human Ammon's horn. Anat Embryol 173:105-110.

Paysan J, Coggan JS, Conroy WG, Berg DK (2000) The neurofilament infrastructure of a developing presynaptic calyx. J Comp Neurol 425:284-294.

Peng X, Gerzanich V, Anand R, Wang F, Lindstrom J (1997) Chronic nicotine treatment up-regulates $\alpha 3$ and $\alpha 7$ acetylcholine receptor sub- 
types expressed by the human neuroblastoma cell line SH-SY5Y. Mol Pharmacol 51:776-784.

Radcliffe KA, Dani JA (1998) Nicotinic stimulation produces multiple forms of increased glutamatergic synaptic transmission. J Neurosci 18:7075-7083.

Rao A, Cha EM, Craig AM (2000) Mismatched appositions of presynaptic and postsynaptic components in isolated hippocampal neurons. J Neurosci 20:8344-8353.

Samuel N, Wonnacott S, Lindstrom J, Futerman AH (1997) Parallel increases in $\left[\alpha^{-125} \mathrm{I}\right]$ bungarotoxin binding and $\alpha 7$ nicotinic subunit immunoreactivity during the development of rat hippocampal neurons in culture. Neurosci Lett 222:179-182.

Schinder AF, Poo MM (2000) The neurotrophin hypothesis for synaptic plasticity. Trends Neurosci 23:639-645

Schuman EM (1999) Neurotrophin regulation of synaptic transmission. Curr Opin Neurobiol 9:105-109.

Seguela P, Wadiche J, Dineley-Miller K, Dani JA, Patrick JW (1993) Molecular cloning, functional properties, and distribution of rat brain $\alpha 7$ : a nicotinic cation channel highly permeable to calcium. J Neurosci 13:596-604.
Turrigiano GG, Nelson SB (2000) Hebb and homeostasis in neuronal plasticity. Curr Opin Neurobiol 10:358-364.

Turrini P, Casu MA, Wong TP, De Koninck Y, Ribeiro-Da-Silva A, Cuello AC (2001) Cholinergic nerve terminals establish classical synapses in the rat cerebral cortex: synaptic pattern and age-related atrophy. Neuroscience 105:277-285.

Tyler WJ, Pozzo-Miller LD (2001) BDNF enhances quantal neurotransmitter release and increases the number of docked vesicles at the active zones of hippocampal excitatory synapses. J Neurosci 21:4249-4258.

Zafra F, Castren E, Thoenen H, Lindholm D (1991) Interplay between glutamate and gamma-aminobutyric acid transmitter systems in the physiological regulation of brain-derived neurotrophic factor and nerve growth factor synthesis in hippocampal neurons. Proc Natl Acad Sci USA 88:10037-10041.

Zarei MM, Radcliffe KA, Chen D, Patrick JW, Dani JA (1999) Distributions of nicotinic acetylcholine receptor $\alpha 7$ and $\beta 2$ subunits on cultured hippocampal neurons. Neuroscience 88:755-764.

Zoli M, Jansson A, Sykova E, Agnati LF, Fuxe K (1999) Volume transmission in the CNS and its relevance for neuropsychopharmacology. Trends Pharmacol Sci 20:142-150. 